\title{
SISTEM INTERNET OF THINGS (IOT) BERBASIS CLOUD COMPUTING DALAM CAMPUS AREA NETWORK
}

\author{
Oris Krianto Sulaiman ${ }^{1}$, Adi Widarma ${ }^{2}$ \\ ${ }^{1}$ Universitas Islam Sumatera Utara \\ JL. SM.Raja Teladan Medan \\ HP: 082369783801 \\ Oris.ks@ft.uisu.ac.id \\ ${ }^{2}$ Universitas Negeri Medan \\ JL. Willem Iskandar Pasar V Medan 20221
}

\begin{abstract}
ABSTRAK
Era teknologi berkembang pesat seiring dengan kebutuhan akan permasalahan yang timbul. Beragam permasalahan yang timbul ini dapat diatasi dengan teknologi, baik di bidang pendidikan, pertanian, kedokteran dan lain-lain tak lepas dari peran teknologi, teknologi yang paling dibutuhkan saat ini adalah internet. Segala sesuatu bentuk perkerjaan akan dapat diatasi dengan teknologi internet yang tidak lepas dari perangkat pendukungnya. Internet of Thing (IoT) merupakan teknologi yang menggunakan internet sebagai sarana dalam melakukan sesuatu, sistem IoT sangat membantu dalam menyelesaikan permasalahan seperti dalam bidang pendidikan dalam jaringan Campus Area Network dengan menggunakan e-learning, membangun sistem digital-library, akses journal online, Usaha Kecil Menengah (UKM) online, sistem informasi universitas, e-mail universitas, dan lain-lain, keseluruhan sistem IoT itu akan membutuhkan wadah untuk menyimpan sumberdaya dari pemakaian sarana IoT, tempat penyimpanan ini menggunakan sistem yang di sebut dengan cloud computing (komputasi awan) dimana penyimpanan ini berupa server dan storage khusus yang berada didalam jaringan internet. IoT akan berintegrasi dengan cloud computing untuk penyimpanan data sehingga mudah dan efisien serta aman dalam penggunaannya.
\end{abstract}

Kata Kunci: Internet of Thing (IoT), Cloud Computing, CAM, e-learning, digital library

\section{PENDAHULUAN}

Pendidikan merupakan pembentukan awal karakter manusia, membangun karakter yang terdidik harus selalu dilakukan dengan beragam cara-cara yang tepat. Pada zaman teknologi sekarang ini telah berkembang akses internet yang cukup luas untuk memenuhi berbagai kebutuhan. Salah satu manfaat dari akses internet ini adalah dalam bidang pendidikan, pendidikan modern cenderung memanfaatkan teknologi komputer dan jaringan seperti pada proses belajar dan mengajar.

Dalam pendidikan skala kampus banyak masalahmasalah yang dapat diselesaikan dengan menggunakan komputer dan jaringan internet. Masalah-masalah tersebut dapat timbul baik dari dosen, mahasiswa maupun pegawai yang ada di kampus tersebut, contoh dari masalah ini adalah pengisian KRS yang masih manual, pembelajaran yang bersifat tradisional dan kurangnya interaksi dengan kampus-kampus lainnya karena keterbatasan jarak serta kurangnya workshop tentang cara mengajar yang baik bagi guru maupun dosen. Internet of Things dapat menyelesaikan masalahmasalah yang timbul dalam dunia pendidikan. Sistem penggunaan internet secara keseluruhan untuk memenuhi aktifitas kampus akan sangat banyak mendapat manfaat terlebih jika sistem Internet of Things ini mempunyai kehandalan jika berintegrasi dengan cloud computing.

\section{TINJAUAN PUSTAKA}

A. Internet of Things

IoT merupakan segala aktifitas yang pelakunya saling berinteraksi dan dilakukan dengan memanfaatkan internet [1] [2] [3]. Dalam penggunaan nya Internet of Thing banyak ditemui dalam berbagai aktifitas, contohnya : banyaknya transportasi online, e-commerce, pemesanan tiket secara online, live streaming, e-learning dan lain-lain bahkan sampai alat-alat untuk membantu dibidang tertentu seperti remote temperature sensor, GPS tracking, and sebagainya yang menggunakan internet atau jaringan sebagai media untuk melakukannya.

Dengan banyaknya manfaat dari Internet of Things maka membuat segala sesuatu nya lebih mudah, dalam bidang pendidikan IoT sangat diperlukan untuk melakukan segala aktifitas dengan menggunakan sistem dan tertata serta sistem pengarsipan yang tepat. 


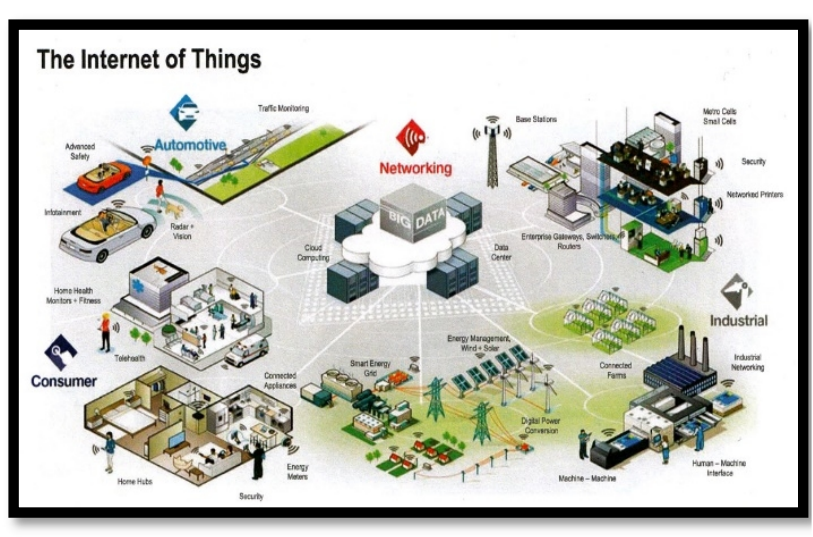

Gbr. 1 Internet of Things

Pada gambar diatas terlihat semua aktifitas terhubung ke pusat internet dan data tersebut di simpan di server baik menggunakan data center maupun cloud computing.

\section{B. Cloud computing}

Merupakan tekonologi yang memberikan pelayanan secara luas dengan akses internet dimanapun berada, media penyimpanan cloud computing berada di internet [4] [5].

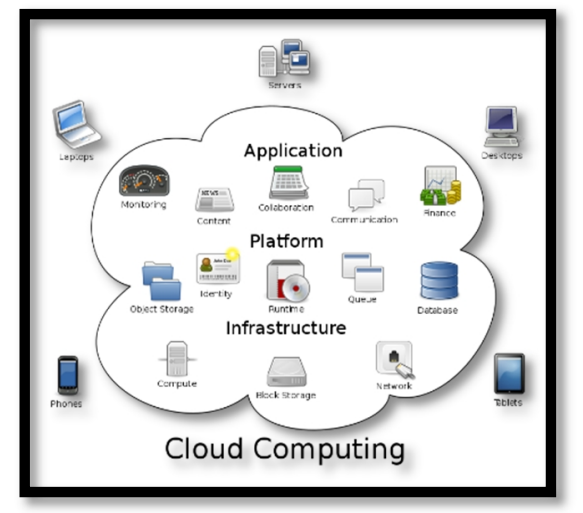

Gbr. 2 Cloud Computing

Cloud computing menyimpan semua data di server yang tidak tau dimana letak server tersebut. Ada 3 layanan cloud computing yang dapat digunakan yaitu [4] [6] :

\section{Software as a Service (SaaS)}

Layanan cloud computing dimana pengguna dapat menggunakan aplikasi atau perangkat lunak (software) yang disediakan oleh cloud provider (penyedia jasa cloud computing).

Contoh dari layanan SaaS adalah :

- Layanan produktivitas: Office365, GoogleDocs, Adobe Creative Cloud.

- Layanan email: Gmail, YahooMail, LiveMail.
- Layanan social network: Facebook, Twitter, Tagged.

- Layanan instant messaging: Yahoo Messenger, Skype, GTalk.

2. Platform as a Service (PaaS)

Layanan yang difasilitasi oleh cloud provider untuk menyediakan platform bagi pengembangan aplikasiaplikasi. Pengguna dapat berfokus pada pengembangan aplikasi tanpa perlu mengkhawatirkan platform aplikasi tersebut.

Contoh dari layanan PaaS adalah : Amazon Web Service, Windows Azure, dan GoogleApp Engine.

\section{Infrastructure as a Service (IaaS)}

Pada layanan ini pengguna dapat menyewa infrastruktu yang di sediakan oleh cloud provider (unit komputasi, storage, memory, network, dan sebagainya). Pada layanan ini seluruhnya pengguna yang menentukan perangkat perangkat untuk cloud computing yang akan digunakan, jika sistem virtual di cloud tersebut menggunakan source yang besar, pengguna dapat menambahkan ram sesuai kebutuhan.

Contoh dari layanan IAAS adalah : Amazon EC2, Rackspace Cloud, Windows Azure,

\section{Campus Area Network}

Kumpulan dari Local Area Network (LAN) yang membentuk sebuah jaringan di ruang lingkup kampus [7]. Jaringan jaringan ini akan menghubungkan setiap gedung yang ada di kampus seperti gedung-gedung perkuliahan. CAM menggunakan model hierarchical network untuk mengoptimalkan jaringaa yang ada di kampus tersebut [8]. Model hierarchical network mempunyai 3 lapisan utama dalam pembentukan jaringan yaitu : core layer, distribution layer dan access layer.

Core layer merupakan lapisan utama dimana pada lapisan ini adalah sumber internet ke seluruh kampus, pada lapisan ini terdapat server yang kemudian layanan akan didistribusikan oleh lapisan ke 2 yaitu distribution layer dan akan diteruskan ke end user di lapisan access layer.

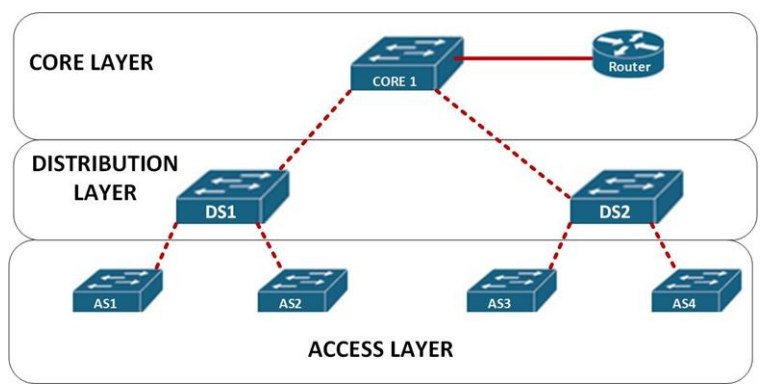

Gbr. 3 hierarchical network 


\section{HASIL DAN PEMBAHASAN}

Dalam jaringan kampus atau dikenal dengan campus area network sangat bagus diterapkan untuk penanganan jaringan di dalam kampus tersebut karena sudah terdapat redundancy di setiap link yang terkoneksi, dengan menggunakan sistem Internet of Things yang di integrasikan dengan cloud computing maka pemanfaatan jaringan di kampus tersebut dalam pendidikan dapat menjadi lebih baik.

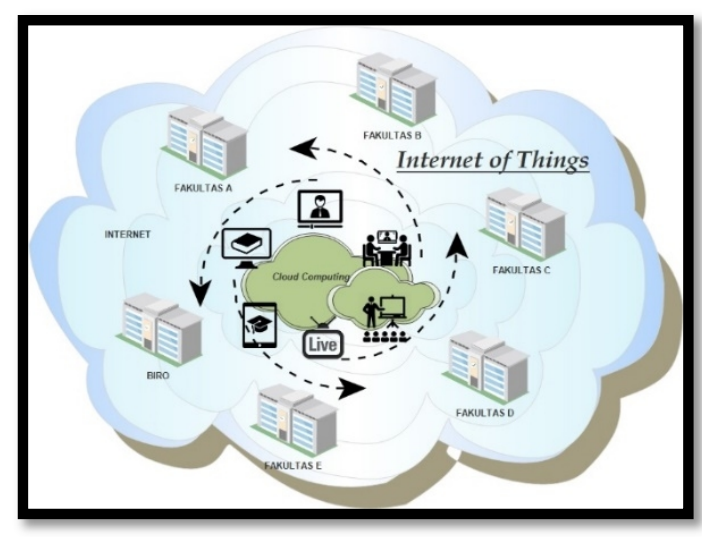

Gbr. 4 Konsep IoT kampus

Dalam ekosistem pengguna di kampus dapat dilihat beberapa kriteria penting yaitu connectivity, content dan community. Connectivity [9]. Connectivity merupakan akses internet, intranet dan extranet untuk layakan koneksi sumber daya yang ada dikampus tersebut. Content merupakan layanan yang sangat penting untuk kampus seperti aplikasi-aplikasi kebutuhan kampus dan yang terakhir adalah community dalam aspek pendidikan sangat dibutuhkan sebuah komunitas untuk mengembangkan ide-ide kreativitas yang akan dimunculkan dari setiap diskusi, layanan ini dapat dibantu dengan sistem mobile application.

Seluruh pekerjaan dalam kampus tersebut menggunakan internet sebagai sarana untuk mempermudah setiap pengerjaan yang kemudian seluruh data hasil pekerjaan tersebut akan disimpian dalam cloud, adapun beberpaa yang dapat dihasilkan dengan menggunakna sistem ini adalah e-learning, distance learning, digital library, campus ecommerce, campus community, system information.

\section{A. E-learning}

Sistem IoT sangat bermanfaat dalam penggunaan sebagai e-learning, yaitu pembelajaran secara elektronik. Internet of Things akan menyediakan kebutuhakan akses untuk penerapan pembelajaran secara elektronik dengan integrasi cloud computing dosen akan dengan mudah mengakses bahan-bahan ajar.
Dosen dapat mengambil bahan ajar yang tersedia di cloud serta dosen dapat mengupload bahan ajar ke cloud sehingga bahan ini dapat digunakan untuk keperluan mahasiswa, tidak hanya bahan berupa presentase dukungan cloud dapat menyimpan video ketika dosen mengajar, video ini perlu ketika ada mahasiswa tidak paham dengan materi yang disampaikan maka mahasiswa dapat mempelajari ulang video tersebut. Bahan ajar ini tersimpan di cloud agar dapat di ambil kapan saja dan keamanannya juga terjaga.

\section{B. Distance Learning}

Pembelajaran jarak jauh atau merupakan metode pembelajaran dimana antara si pengajar dan yang di ajar tidak bertemu secara langsung tetapi menggunakan media-media tertentu untuk melangsungkan proses belajar mengajar. Pembelajaran jarak jauh sangat besar manfaatnya dalam penggunaan. Contoh pembelajaran jarak jauh yang menggunakan internet adalah video conference.

Dengan adanya distance learning pengajar tidak perlu harus ke lokasi tujuan, dengan menggunakan IoT dan sistem cloud maka akan dapat dibuat jaringan khusus atau extanet seperti Indonesian Research and Education Network (IdRen) dimana jaringan khusus yang menghubungkan antar kampus untuk kepentingan pendidikan, contoh UI mengadakan workshop mengenai pembedahan tubuh manusia kemudian kampus-kampus lain yang tergabung kedalam IdRen tersebut dapat melihat workshop tersebut dengan menggunakan distance learning. Hasil-hasil dari pembelajaran ini akan disimpan ke dalam cloud sehingga jika sewaktuwaktu ingin di akses maka sistem dapat menyediakan layanannya.

\section{Digital Library}

Dengan adanya sistem Internet of Things (IoT) dan diintegrasi dengan cloud computing membuat pengelolaan perpustakaan menjadi digital library. Perpustakaan digital biasanya menempatkan file-file digital seperti e-book, e-journal, dan lainnya ke dalam server lokal. Dengan IoT diintegrasikan cloud computing maka file-file digital tersebut akan tersimpan di cloud, sistem cloud ini banyak digunakan sebagai backup.

Proses peminjaman dan pengembalian buku dapat dilakukan dengan mengakses web digital library, tetapi yang dapat mengakses hanya mahasiswa pada kampus tersebut, atau hanya untuk extranet. File-file kebutuhan perpustakaan ini akan di simpan di dua tempat yaitu di sever lokal yaitu pada core layer dan pada sistem cloud di luar kampus sebagai backup dan penyimpanan yang aman, sehingga file-file tersebut tetap terjaga. 


\section{E-Commerce}

Dalam kampus terdapat Usaha Kecil Menengah (UKM) sebagai wujud kreativitas mahasiswa, UKM dengan sistem Internet of Things segala sesuatu akan dilakukan dengan menggunakan internet termasuk UKM. UKM akan menggunakan e-commerce atau perdagangan digital. Hasil yang di perjual belikan oleh mahasiswa akan di lakukan secara online.

Cloud akan menjadi wadah produk produk yang dihasilkan oleh UKM ini. Layanan cloud dengan Software as a Service (SaaS) sangat membantu dalam pelayanan ecommerce.

\section{E. Campus Community}

Dalam sebuah kampus ada banyak komunitaskomunitas yang di bentuk oleh mahasiswa, untuk menjadikan komunitas tersebut menjadi lebih produktif dapat dilakukan dengan menggunakna Internet of Things, setiap mahasiswa tersebut mempunyai kartu komunitas yang dapat dimanfaatkan secara gratis antar sesame komunitas.

IoT juga berperan untuk menghubungkan beberapa komunitas di tiap kampus unutk mengadakan diskusi. Diskusi komunitas tidak perlu menentukan lokasilokasi tertentu tetapi dapat dilakukan dengan video streaming.

Saat ini hampir semua mahasiswa mempunyai gadget atau smartphone yang digunakan disetiap aktifitas, siswa-siswa sekolah lebih banyak menghabiskan waktu dengan gadget atau smartphone. Ada beberapa manfaat dari smartphone, selain untuk komunikasi diantaranya bisa berselancar di dunia maya, chatting, dan lainnya. Dalam IoT smartphone ini juga merupakan bagian yang penting untuk hubungan sosial antar komunitas.

Aplikasi chatting seperti whatsapp, BBM, catfish dan lainnya adalah aplikasi yang umum digunakan masyarakat ramai sekarang ini. Campus Community menggunakan kartu smartphone, kartu komunitas ini membuat fasilitas-fasilitas di aplikasi komunitas terutama fasilitas chatting dengan kelompok komunitas lainnya. Selain itu juga dengan menggunakan kartu smartphone khusus ini maka mahasiswa dapat saling menggunakan fasilitas telpon gratis. Tiap komunitas yang terhubung ke extranet akan mendapatkan penyimpanan cloud dengan size tertentu untuk membuat penyimpanan log dan file-file yang ingin di bagikan ke komunitas lainnya, sehingga ketika komunitas dari kampus lain ingin memanfaatkan sumber daya yang di bagikan tersebut, si pembagi sumber daya cukup dengan memberikan link dan akses ke sumber daya tersebut.

\section{E. System Information}

Internet of Things (IoT) sangat mendukung sistem informasi universitas atau kampus, content yang memuat semua kebutuhan mahasiswa ada di sistem informasi. Data dari sistem informasi ini di integrasikan dengan cloud computing dengan menggunakan cloud computing data tersebut lebih aman dan dapat digunakan kapan saja. Semua informasi akan ditampilkan secara online dan setiap aktifitas atau acara seminar dapat dimuat secara live streaming dan ditampilkan di sistem informasi.

\section{KESIMPULAN}

Sistem Internet of Things (IoT) merupakan segala bentuk aktifitas yang dilakukan dengan menggunakan media akses. Dengan adanya IoT segala bentuk aktifitas kampus menjadi mudah serta dengan adanya cloud membuat sistem IoT menjadi semakin efisien. Data dari semua aktifitas kampus di simpan dalam cloud sehingga mudah diambil kapan saja dan dimana saja serta keamanannya yang terjamin. Dengan menggunakan sistem ini nantinya akan mengurangi pekerjaan manual dan akan mengurangi pemakaian kertas. Untuk menjalankan IoT yang terintegrasi cloud computing harus memenuhi akses bandwidth yang cukup serta storage yang besar.

\section{REFERENSI}

[1] M. P. T. Sulistyanto and D. A. Nugraha, "Implementasi IoT (Internet of Things) dalam pembelajaran di Universitas Kanjuruhan Malang," SMARTICS Journal, pp. 20-23, 2015.

[2] D. Prihatmoko, "PENERAPAN INTERNET OF THINGS ( IoT ) DALAM PEMBELAJARAN DI," Jurnal SIMETRIS, pp. 567-574, 2016

[3] E. D. Meutia, "Internet of Things - Keamanan dan Privasi," Seminar Nasional dan Expo Teknik Elektro, pp. 85-89, 2015.

[4] a. "Studi Perbandingan Layanan Cloud Computing," Jurnal Rekayasa Elektrika, vol. 10, no. 4, pp. 193-201, 2013.

[5] E. Rusnandi and D. Susanti, "PERENCANAAN STRATEGIS CLOUD COMPUTING TECHNOLOGY BERBASIS Gafe (GOOGLE APPS For EDUCATION ) BAGI PERGURUAN TINGGI SWASTA DI WILAYAH III CIREBON PROPINSI JAWA BARAT," Jurnal Computech \& Bisnis, vol. 6, no. 1, pp. 1-16, 2012.

[6] A. Budiyanto, Pengantar Cloud Computing, CloudIndonesia, 2012.

[7] O. K. Sulaiman, "SIMULASI PERANCANGAN SISTEM JARINGAN INTER VLAN ROUTING DI UNIVERSITAS NEGERI MEDAN," CESS (Journal of Computer Engineering, System and Science), vol. 2, no. 1, pp. 92-96, 2017.

[8] O. K. Sulaiman, M. Ihwani and M. Basri, "Model Hierarki Network dengan Menggunakan Spanning Tree Protocol (STP) dan Hot Standby Router Protocol (HSRP)," in Seminar Sehari Program Pascasarjana Informatika (SENOPATI), Medan, 2015.

[9] T. Indonesia, "The Future of Business and ICT Trends Universitas Negeri Medan," Telkom Indonesia, Medan, 2017. 